\title{
Early activation of object names in visual search
}

\author{
ANTJE S. Meyer \\ University of Birmingham, Birmingham, England \\ EVA BELKE \\ University of Bielefeld, Bielefeld, Germany \\ AND \\ Anna L. Telling and Glyn W. Humphreys \\ University of Birmingham, Birmingham, England
}

\begin{abstract}
In a visual search experiment, participants had to decide whether or not a target object was present in a fourobject search array. One of these objects could be a semantically related competitor (e.g., shirt for the target trousers) or a conceptually unrelated object with the same name as the target-for example, bat (baseball) for the target bat (animal). In the control condition, the related competitor was replaced by an unrelated object. The participants' response latencies and eye movements demonstrated that the two types of related competitors had similar effects: Competitors attracted the participants' visual attention and thereby delayed positive and negative decisions. The results imply that semantic and name information associated with the objects becomes rapidly available and affects the allocation of visual attention.
\end{abstract}

In many everyday tasks (e.g., reading, driving), we must direct our visual attention to appropriate stimuli at the appropriate times. The control of visual attention has often been studied in visual search paradigms, wherein participants decide as quickly as possible whether or not a target is part of a search display. Current models of selective visual attention assume that search performance is determined by competition among visual stimuli, which is moderated by bottom-up and top-down influences (see Desimone \& Duncan, 1995; Duncan \& Humphreys, 1989). Top-down influences can be modulated by a "template" for the target, which can prime the representation of an object in a search display, biasing attentional selection toward it (Chelazzi, Miller, Duncan, \& Desimone, 1993; Hodsoll \& Humphreys, 2001, 2005; Soto, Heinke, Humphreys, \& Blanco, 2005).

The working memory representation of the target will often be linked to knowledge about the object stored in long-term memory. Moores, Laiti, and Chelazzi (2003) demonstrated the existence of associative effects on the allocation of visual attention during visual search. They showed participants four-object displays that could include an associate to the target-for instance, a crash helmet when the target was a motorbike. The presence or absence of an associate did not affect the participants' response speed or accuracy on target-present trials, but on target-absent trials, they responded more slowly and less accurately when the associate was present. Eyemovement analyses showed that, on target-present and target-absent trials, the first saccade after display onset was more often directed to the associate than to an unrelated control object. On target-present trials, most initial saccades were directed to the target, but the likelihood of first saccades to the target was reduced by the presence of an associate. These findings suggest that activation spreads from targets to associatively related representations. Because of this, the related object in the display is primed and competes with the target more efficiently, relative to unrelated objects, for the allocation of visual attention (see also Dahan \& Tanenhaus, 2005; Huettig \& Altmann, 2005).

The long-term memory representations of most common objects are connected to lexical entries specifying their names. A lexical entry consists of a semantic-syntactic representation of a word (the lemma) and representations of its morphological and phonological form (e.g., Dell, 1986; Levelt, Roelofs, \& Meyer, 1999). Several studies have shown that names of common objects become rapidly activated even when the objects are presented extrafoveally (e.g., Morgan \& Meyer, 2005) and when speakers do not intend to name them, but plan to name other simultaneously present objects (Meyer \& Damian, 2007; Morsella \& Miozzo, 2002; Navarette \& Costa, 2005). However, in all of these studies, participants were engaged in naming tasks. It is as yet unclear whether lexical representations become activated in search as well and influence competition with the target for selection. We examined this issue here. 
In the experiment reported in this article, participants saw target objects, followed by four-object search displays, half of which included the target. On a quarter of these target-present displays and a quarter of the remaining, target-absent displays, one of the objects was conceptually unrelated to the target, but had a homophonous name (e.g., bat [animal] and bat [baseball]). Homophones have distinct conceptual representations and lemmas, but their lexical representations are closely linked because they share all phonological segments and possibly the morphological representation (Jescheniak \& Levelt, 1994; Miozzo \& Caramazza, 2005). In order to compare the effects of homophonous competitors with those of semantically related ones, we included trials wherein the search display featured an associatively or categorically related competitor or an appropriate control object. If the objects presented in visual search activate their names, a strong lexical relationship between homophonous targets and competitors might have similar effects to a strong semantic relationship: The presence of homophonous competitors might delay responses, and participants' first saccades might be directed at such competitors more often, relative to unrelated control objects. By contrast, if access to object names is not an automatic consequence of object recognition, but occurs only when the task requires verbal labeling of the objects (e.g., Zelinsky \& Murphy, 2000), only the presence of semantically related, but not homophonous, competitors should affect participants' response latencies and eye movements.

\section{METHOD}

\section{Participants}

A total of 14 undergraduate students at the University of Birmingham participated, in exchange for payment. They all reported having normal or corrected-to-normal vision, and were native speakers of English.

\section{Design and Materials}

On each trial, the participants saw a target picture followed by a four-object search display. On half of the trials (target present), the display included the target. On half of these trials and on half of the remaining (target-absent) trials, related competitors were present. There were two types of related competitors: objects with homophonous names and semantically related objects.

Two sets of 56 pictures each were selected from Snodgrass and Vanderwart (1980) and from a picture gallery provided by the Max Planck Institute for Psycholinguistics, Nijmegen, The Netherlands (see the Appendix). In the homophone set, 14 pictures served as targets and 14 others, with homophonous names, as related competitors. The remaining 28 pictures were used as unrelated fillers. The semantic set also included 14 targets, 14 competitors (members of the same semantic category or associates to the target), and 28 unrelated fillers. The visual similarity of 25 of the 28 target-competitor pairs had been assessed in a paper-and-pencil rating study by Belke, Humphreys, Watson, and Meyer (2006), wherein 14 participants rated the visual similarity of object pairs on a scale ranging from 1 (very dissimilar) to 5 (very similar). The ratings for the targetcompetitor pairs were low (median ratings: 1.25 for semantically related pairs and 1 for homophones) and significantly different from the ratings for 24 pairs, such as pencil-needle, that had been specifically selected to be visually similar (median rating: $4.25 ; z_{1}=3.34$, Wilcoxon signed rank test; $z_{2}=4.55$, Mann-Whitney $U$ test, both $p s<.001$ for the comparison of semantically related vs. visually similar pairs $z_{1}=3.32 ; z_{2}=4.62$, both $p$ s $<.001$ for the comparison of homophones vs. visually similar pairs). The median rating for the semantically related pairs was slightly, but significantly higher than the median rating for 12 pairs, such as tie-swan, that had been specifically selected to be conceptually and visually as dissimilar as possible (mean ratings: 1.25 and $1, z_{1}=2.34, z_{2}=2.40$, both $p$ s $<$ $.05)$. The median ratings for the homophones and the visually dissimilar pairs were both 1 .

In the condition in which the target and competitor were present, the related target-competitor pairs were shown, along with two fillers. In the target-absent conditions, the target was replaced by another member of the target set-that is, a picture serving as a target on a different trial. Analogously, in the competitor-absent conditions, the related competitor was replaced by an unrelated member of the competitor set (see Table 1). Thus, each search display featured a member of the target set, a member of the competitor set, and two filler objects, which were semantically and phonologically unrelated to the remaining objects in the display.

For each target and condition, we selected two different fillers. We also created two versions of each display, which differed in the leftright orientation of the objects. This yielded 448 different search displays (28 targets $\times 4$ conditions $\times 2$ sets of fillers $\times 2$ orientations). In the target-present condition, the search target was shown in the same orientation as the corresponding object in the search display.

The line drawings were scaled to fit frames of $100 \times 100$ pixels, corresponding to $4.6^{\circ} \times 4.6^{\circ}$ at a viewing distance of $60 \mathrm{~cm}$. The four objects shown together in a display were similar in visual complexity, measured as the proportion of black pixels in the $100 \times 100$ pixel frames. They were positioned in a circle around the midpoint of the screen (see Figure 1), at a distance (midpoint screen to midpoint picture) of $7.4^{\circ}$. The objects were randomly allocated to the four screen positions.

The 448 displays were distributed over four blocks of 112 trials each. In each block, all of the targets were shown once in each condition. The same orientation of the objects was used in Blocks 1 and 2 and in Blocks 3 and 4, and the same fillers were used in Blocks 1 and 3 and in Blocks 2 and 4. A different random order of the displays was used for each block and each participant.

\section{Apparatus}

The experiment was controlled by a $1.5-\mathrm{GHz}$ Pentium IV computer. The stimuli were displayed on a 17 -in. Trinitron Multiscan G240 monitor, with a screen resolution of $600 \times 800$ pixels. Eye movements were recorded using a head-mounted eyetracker (SMI Eyelink Version 2.04, SR Research Ltd.) at a sampling rate of $250 \mathrm{~Hz}$. Responses were registered using a hand-held response pad (SR Research).

\section{Procedure}

The participants read the instructions and familiarized themselves with the materials by studying a booklet showing all of the objects appearing in the experiment and their names. Then the eyetracker was positioned on the participant's head, the system was calibrated, and the experiment began.

Before each trial, the participant looked at a central fixation point, which allowed the experimenter to carry out a drift correction. The

Table 1

Materials Used in the Four Experimental Conditions (Example From the Homophone Set)

\begin{tabular}{|c|c|c|}
\hline Condition & Target & Search Set \\
\hline $\begin{array}{l}\text { Target Present } \\
\text { Competitor present } \\
\text { Competitor absent }\end{array}$ & $\begin{array}{l}\text { boy } \\
\text { boy }\end{array}$ & $\begin{array}{l}\text { boy, buoy, ant, leaf } \\
\text { boy, flour, chair, scissors }\end{array}$ \\
\hline $\begin{array}{l}\text { Target Absent } \\
\text { Competitor present } \\
\text { Competitor absent }\end{array}$ & $\begin{array}{l}\text { boy } \\
\text { boy }\end{array}$ & $\begin{array}{l}\text { flower, buoy, necklace, horseshoe } \\
\text { (fish) tank, (garden) spade, clock, plug }\end{array}$ \\
\hline
\end{tabular}



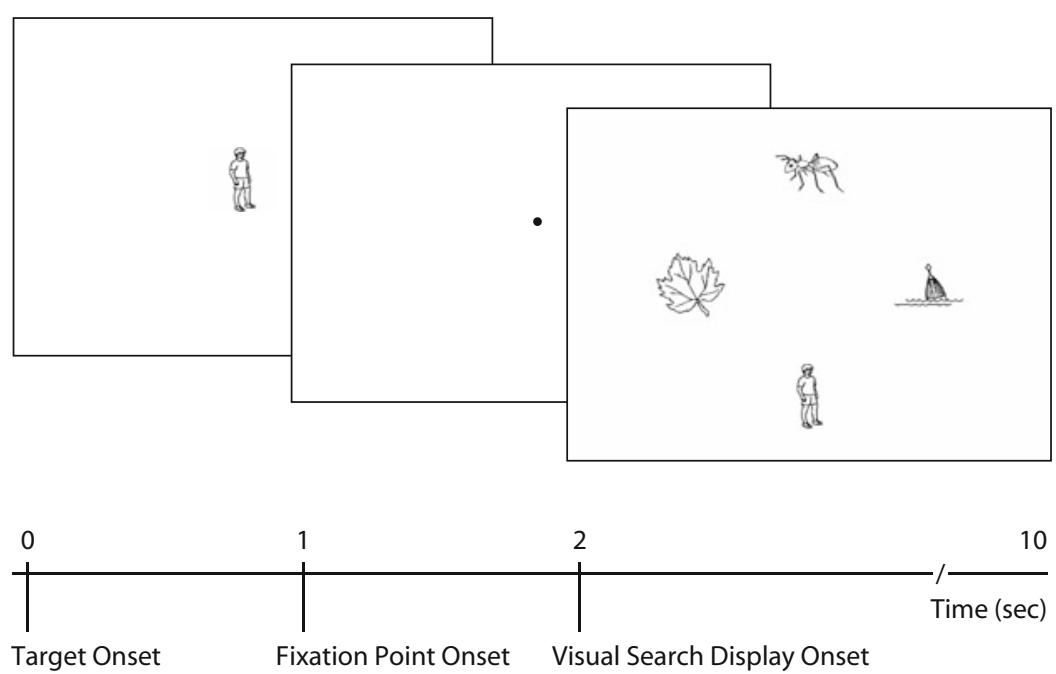

Figure 1. Trial structure.

participant pressed a button to initiate presentation of a search target, which appeared in the center of the screen for $1 \mathrm{sec}$, followed by another fixation point presented for $1 \mathrm{sec}$, and a search display, which was shown until the participant responded. Participants pressed the left or right button of the response pad to indicate target presence or absence. Each test block took approximately $10 \mathrm{~min}$. There were short breaks between blocks.

After the experiment, the participants were given another booklet showing the materials, and were asked to write down the names of the objects. In order to establish whether there were any effects of name relatedness between targets and competitors, it was crucial that the objects were primarily associated with the expected names. Therefore, we excluded from the analyses all of the trials of the main experiment featuring targets or competitors that a participant had named incorrectly in the posttest (4.9\% of the trials). The first five trials of the experiment were considered practice trials and were also excluded from the analyses.

\section{RESULTS}

\section{Errors}

Participants were significantly more likely to make errors on target-absent than on target-present trials [4.3\% vs. $1.7 \%$; by-participants analysis, $F_{1}(1,13)=17.43, p<$ $.001, \eta_{\mathrm{p}}^{2}=.57$; by-items analysis, $F_{2}(1,26)=21.67, p<$ $\left..001, \eta_{\mathrm{p}}^{2}=.46\right]$, and they made more errors on trials using the semantic set than on trials using the homophone set $\left[3.5 \%\right.$ vs. $2.4 \% ; F_{1}(1,13)=10.04, p<.01, \eta_{\mathrm{p}}^{2}=.44$; $\left.F_{2}(1,26)=4.14, p<.06, \eta_{\mathrm{p}}^{2}=.14\right]$. The error rate was not affected by the presence or absence of a related competitor (3.0\% for both conditions), and there were no interactions. Error trials were excluded from further analysis, as were all trials wherein a participant's response latency deviated from his/her overall mean by more than $3 S D$ s (1.6\% of the trials).

\section{Response Latencies}

For the response latencies, very similar results were obtained for the semantic and the homophone set (see Figure 2). Responses were significantly faster on targetpresent than on target-absent trials $\left[F_{1}(1,13)=44.93\right.$, $\eta_{\mathrm{p}}^{2}=.78 ; F_{2}(1,26)=208.67, \eta_{\mathrm{p}}^{2}=.89$, both $\left.p \mathrm{~s}<.001\right]$ and on competitor-absent than on competitor-present trials $\left[F_{1}(1,13)=45.19, \eta_{\mathrm{p}}^{2}=.78, p<.001 ; F_{2}(1,26)=\right.$

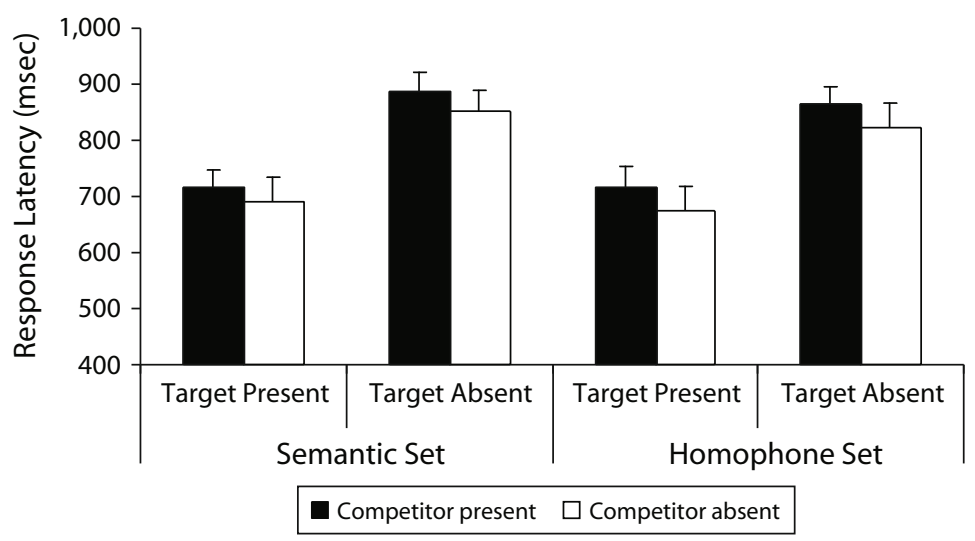

Figure 2. Mean response latency per condition with standard errors (by participants). 
$\left.11.91, p<.01, \eta_{\mathrm{p}}^{2}=.32\right]$. Reactions were faster in the homophone set than in the semantic set, but this effect was significant by participants only $\left[F_{1}(1,13)=5.29, p<\right.$ $\left..05, \eta_{\mathrm{p}}^{2}=.29 ; F_{2}(1,26)=2.64, p<.12, \eta_{\mathrm{p}}^{2}=.09\right]$ and did not interact with the effect of competitor presence or target presence. There were no other interactions. In sum, responses were delayed by the presence of semantically related as well as homophonous competitors.

\section{Eye Movements}

For the analyses of eye movements, five regions of interest were defined: a circular region around the fixation point (24 pixels in diameter) and a square $(108 \times 108$ pixel $)$ region around each of the four objects. We excluded $8 \%$ of the trials from the analyses because the participants did not look at the fixation point at trial onset and a further $4 \%$ because participants inspected none of the object regions before responding. For the remaining trials, we examined when the first saccade to an object was initiated, which object was fixated first, and how long each object was inspected.

The first saccade toward an object was initiated significantly earlier when the target was present than when it was absent [211 vs. $225 \mathrm{msec}$ after trial onset; $F_{1}(1,13)=$ $25.20, \eta_{\mathrm{p}}^{2}=.66 ; F_{2}(1,26)=26.89, \eta_{\mathrm{p}}^{2}=.51$, both $p \mathrm{~s}<$ $.001]$. It was initiated earlier in the competitor-present than in the competitor-absent condition, but this difference ( 216 vs. $220 \mathrm{msec}$ ) was only significant in the analysis by participants $\left[F_{1}(1,13)=4.99, p<.05, \eta_{\mathrm{p}}^{2}=.28\right]$. There were no other main effects on saccade latencies or interactions.

Figure 3 shows the percentages of all first saccades that were directed at the targets in the target-present condition or at the foils replacing the targets in the targetabsent condition. As noted above, these foils were targets on other trials. The results were again very similar for the semantic and the homophone set. As expected, there were far more fixations to the targets on target-present trials than to the foils on target-absent trials [63\% vs. $22 \%$; $F_{1}(1,13)=193.53, \eta_{\mathrm{p}}^{2}=.94 ; F_{2}(1,26)=245.66, \eta_{\mathrm{p}}^{2}=$ .94 , both $p$ s $<.001]$. More interestingly, targets and foils were significantly less likely to be fixated after the first saccade in the presence (relative to the absence) of a related competitor $\left[40 \%\right.$ vs. $45 \% ; F_{1}(1,13)=14.74, p<$ $\left..01, \eta_{\mathrm{p}}^{2}=.53 ; F_{2}(1,26)=7.58, p<.02, \eta_{\mathrm{p}}^{2}=.23\right]$. There were no interactions.

The rates of first fixations to the competitors showed a complementary pattern (see Figure 4). The rate of first fixations to the competitors was much lower in the targetpresent than in the target-absent condition [16\% vs. $32 \%$; $F_{1}(1,13)=72.23, p<.001, \eta_{\mathrm{p}}^{2}=.85 ; F_{2}(1,26)=46.47$, $\left.p<.001, \eta_{\mathrm{p}}^{2}=.64\right]$, and the related competitors were more likely to be fixated than the unrelated control objects replacing them on competitor-absent trials (26\% vs. $22 \%$ ), though this difference was significant across participants only $\left[F_{1}(1,13)=18.85, p<.001, \eta_{\mathrm{p}}^{2}=.59 ; F_{2}(1,26)=\right.$ $\left.2.42, p<.15, \eta_{\mathrm{p}}^{2}=.09\right]$.

The final analysis examined how long the objects were inspected. The first gaze duration was defined as the interval between the onset of the first fixation and the end of the last fixation, in a set of successive fixations to an object. First gaze durations were substantially longer for targets than for the unrelated foils replacing them in the target-absent condition [means: 309 vs. $156 \mathrm{msec}$; $F_{1}(1,13)=101.97, \eta_{\mathrm{p}}^{2}=.89 ; F_{2}(1,26)=536.53, \eta_{\mathrm{p}}^{2}=$ .954 , both $p$ s $<.001$ ]. First gaze durations to competitors (whether related or unrelated to the target) were significantly longer in the target-absent than in the target-present condition $\left[165\right.$ vs. $125 \mathrm{msec} ; F_{1}(1,13)=39.03, \eta_{\mathrm{p}}^{2}=.75$; $F_{2}(1,26)=20.94, \eta_{\mathrm{p}}^{2}=.45$, both $\left.p \mathrm{~s}<.001\right]$. Finally, related competitors were inspected longer than the unrelated control objects taking their place in the competitor-absent condition $\left[152\right.$ vs. $138 \mathrm{msec} ; F_{1}(1,13)=19.10, p<.001$, $\left.\eta_{\mathrm{p}}^{2}=.60 ; F_{2}(1,26)=4.73, p<.05, \eta_{\mathrm{p}}^{2}=.15\right]$.

\section{DISCUSSION}

The present study yielded further evidence for the existence of semantic-relatedness effects in visual search (see also Belke et al., 2006; Moores et al., 2003): (1) Participants responded more slowly in the presence than in the absence of a semantically related competitor, (2) par-

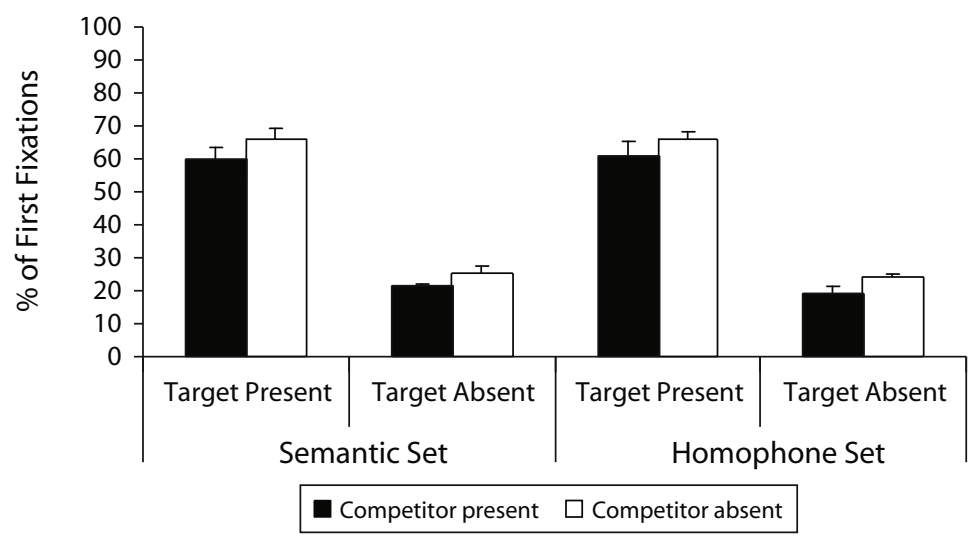

Figure 3. Mean proportions of first fixations to targets (target-present condition) and foils (target-absent condition; error bars represent standard errors, by participants). 


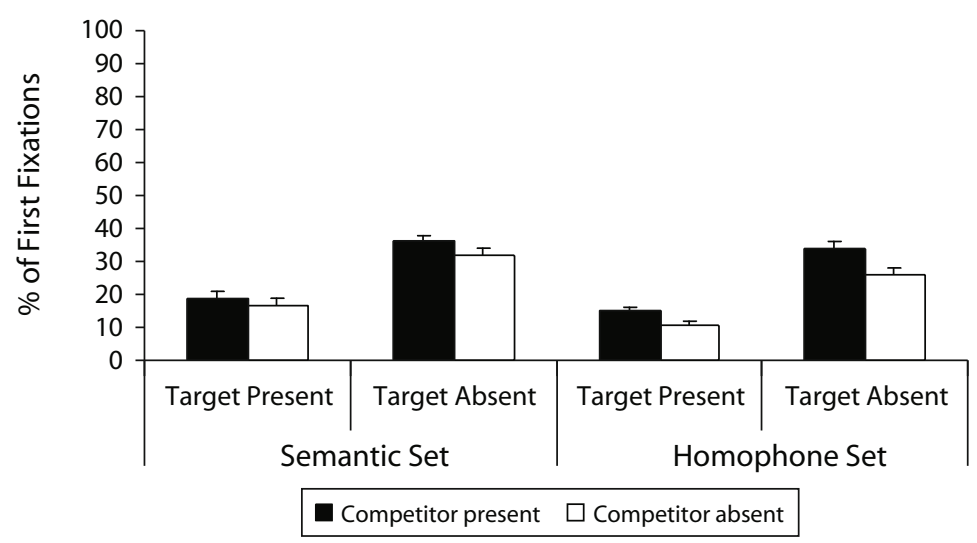

Figure 4. Mean proportions of first fixations to related competitors (competitor-present condition) and unrelated control objects (competitorabsent condition).

ticipants' first saccade after display onset was more likely to be directed toward a related competitor than toward an unrelated control object, and (3) the target, if present, was less likely to be fixated after the first saccade when a related competitor was present than when it was absent. As Moores et al. noted, such semantic-relatedness effects in visual search are likely to be based on semantic priming but cannot be exclusively due to priming. This is because priming should facilitate the processing of one of the objects in the display and should therefore lead to increased response speed and accuracy. However, semantically related competitors have the opposite effect-delaying responses and, in some studies, reducing accuracy. This suggests an effect of competition in the allocation of visual attention, which is increased when a competitor to the target is primed.

The novel result of the present experiment is that homophonous competitors had exactly the same competitive effects as semantically related ones. This demonstrates that in a visual search task, linguistic knowledge associated with the objects becomes activated and affects the search in the same way as does knowledge about the semantic properties of the objects.

Given that the experiment used repeated presentations of items, it is possible that the participants became aware of the relations between the homophone competitors and targets and adopted the strategy of trying to name all of the items present - even though the presence of a homophone disrupted search performance. Note that, even if participants did adopt this strategy, the results are still of interest since they show that the homophone competitors tended to attract attention (influencing the first saccade made during search), suggesting that the names of the objects were accessed prior to the allocation of overt attention in the displays. To test this possibility, we analyzed the data for the first block of trials only. The pattern of performance matched that found when all of the data were included: (1) The reactions in the first block were slower in the presence than in the absence of a homophonous competitor (means: 880 vs. $840 \mathrm{msec}$, compared with 788 vs. $746 \mathrm{msec}$ for the complete data set), (2) the first saccade was less likely to be directed at the target or the unrelated foil replacing it when a homophonous competitor was present than when it was absent (35\% vs. $39 \%$, compared with $40 \%$ and $45 \%$ in the complete data set), and (3) the first fixation was more likely to be directed at the homophonous competitor than at the unrelated control object ( $24 \%$ vs. $20 \%$, compared with $24 \%$ vs. $19 \%$ in the complete data set). ${ }^{1}$ These results suggest that the homophone effect was not contingent on participants strategically naming objects as the experiment progressed.

Our results contrast with findings reported by Zelinsky and Murphy (2000). They carried out a search experiment in which participants decided whether or not a display of four faces included a target face. Prior to the experiment, the participants learned to associate a monosyllabic or trisyllabic name with each of the faces. Zelinsky and Murphy found that the length of the names did not affect how long the participants looked at the faces during the search task, suggesting that the names did not become automatically activated. A possible reason for this difference, in comparison with our results, is that the recently acquired names did not become activated as readily as the overlearned names of the objects we showed. In addition, Zelinsky and Murphy considered the effect of name length, which would arise during phonological encoding, whereas we considered the effects of homophony, which might arise slightly earlier, during access to the morphological forms of the object names.

Further research is necessary to determine exactly how the homophone effects arose. A much debated issue in current psycholinguistics is whether every activated concept automatically activates the corresponding lexical representations, which is the view held by proponents of cascaded models of lexical access (e.g., Caramazza, 1997; Dell, 1986), or whether lexical access is restricted to those units that the speaker selects to be part of an utterance plan, as proposed in serial stage models of lexical access (e.g., Bloem \& La Heij, 2003; Levelt et al., 1999). One account of the homophone effects is that both the search target held in working memory and the objects in the search display activated the associated linguistic 
knowledge, as predicted by cascaded models of lexical access. The homophonous competitor would attract visual attention because it shared an important property-the name-with the target, which was primed when the search target was viewed. Unrelated objects in the search display may also activate their names, but since these items were not primed, they were less potent competitors for the allocation of visual attention. Recent studies (Meyer \& Damian, 2007; Morsella \& Miozzo, 2002; Navarrete \& Costa, 2005) have shown that in object-naming tasks, the names of distractor objects can become activated and affect how fast people name target objects. The present experiment suggests that the names of task-irrelevant objects may become activated even when the viewer does not intend to formulate any utterance at all.

Alternatively, the point of contact between the representations of the target and the homophonous competitor might be at the conceptual, rather than the lexical, level. According to this view, activation spread from the visual representation of the target to the target lemma (e.g., bat [animal]) and its morphological and phonological forms. From these representations, activation spread to the lemma and the conceptual representation of the competitor (bat [baseball]), which were therefore primed when the search display was shown. This view does not presuppose that the lexical representations of the items in the search display become available quickly enough in a bottom-up manner to affect search upon presentation of the display, or, indeed, that there is bottom-up access to these representations at all. It does, however, presuppose that, when the target is processed, activation spreads from its word form to the competitor lemma and its conceptual representation. Serial models of lexical access do not assume such bottom-up spreading activation within the speech production system. However, they can account for the results on the assumption that the participants in the visual search task engaged not only the speech production, but also the speech comprehension system: They first generated the target name in inner speech and then comprehended it, just as inner speech is comprehended in other situations (e.g., when we memorize a speech or a shopping list). In the comprehension system, there are, of course, bottom-up links from word form representations to lemmas and conceptual representations.

For both of these accounts, the data suggest that there is sufficiently rapid access to conceptual information from distractors for this information to influence the first fixations made during search. It may even be that there is sufficiently rapid access to name information from distractors that this too affects the earliest saccades. It is for future research to assess the constraints on access to these high-level representations in search, and whether, for example, distractor names are activated in parallel across the items present.

\section{AUTHOR NOTE}

The authors thank Shana Hoque for carrying out the experiment and Derrick Watson for making the experimental software available. The research was funded by a Nuffield Undergraduate Bursary to G.W.H. and Shana Hoque, by an MRC grant to G.W.H., and by an ESRC grant to A.S.M. Correspondence concerning this article should be addressed to A. S. Meyer, School of Psychology, University of Birmingham,
Edgbaston, Birmingham B15 2TT, England (e-mail: a.s.meyer@bham .ac.uk).

\section{REFERENCES}

Belke, E., Humphreys, G. W., Watson, D. G., \& Meyer, A. S. (2006). Effects of top-down semantic knowledge in visual search are modulated by cognitive but not by perceptual load. Manuscript submitted for publication.

Bloem, I., \& La Heis, W. (2003). Semantic facilitation and semantic interference in word translation: Implications for models of lexical access in language production. Journal of Memory \& Language, 48, 468-488.

Caramazza, A. (1997). How many levels of processing are there in lexical access? Cognitive Neuropsychology, 14, 177-208.

Chelazzi, L., Miller, E. K., Duncan, J., \& Desimone, R. (1993). A neural basis for visual search in inferior temporal cortex. Nature, 363, 345-347.

DAHAN, D., \& TANenhaus, M. K. (2005). Looking at the rope when looking for the snake: Conceptually mediated eye movements during spoken-word recognition. Psychonomic Bulletin \& Review, 12, 453-459.

DELL, G. S. (1986). A spreading-activation theory of retrieval in sentence production. Psychological Review, 93, 283-321.

Desimone, R., \& DunCAN, J. (1995). Neural mechanisms of selective visual attention. Annual Review of Neuroscience, 18, 193-222.

DunCAN, J., \& HuMPhrEYS, G. W. (1989). Visual search and stimulus similarity. Psychological Review, 96, 433-458.

Hodsoll, J., \& Humphreys, G. W. (2001). Driving attention with the top down: The relative contribution of target templates to the linear separability effect in the size dimension. Perception \& Psychophysics, 63, 918-926.

Hodsoll, J., \& Humphreys, G. W. (2005). The effect of target foreknowledge on visual search for categorically separable orientation targets. Vision Research, 45, 2346-2351.

Huettig, F., \& AltmanN, G. T. M. (2005). Word meaning and the control of eye fixation: Semantic competitor effects and the visual world paradigm. Cognition, 96, B23-B32.

Jescheniak, J. D., \& Levelt, W. J. M. (1994). Word frequency effects in speech production: Retrieval of syntactic information and of phonological form. Journal of Experimental Psychology: Learning, Memory, \& Cognition, 20, 824-843.

Levelt, W. J. M., Roelofs, A., \& Meyer, A. S. (1999). A theory of lexical access in language production. Behavioral \& Brain Sciences, 22, 1-38.

MEYER, A. S., \& DAMIAN, M. F. (2007). Activation of distractor names in the picture-picture word interference paradigm. Memory \& Cognition, 35, 494-503.

Miozzo, M., \& CAramazza, A. (2005). The representation of homophones: Evidence from the distractor-frequency effect. Journal of Experimental Psychology: Learning, Memory, \& Cognition, 31, 1360-1371.

Moores, E., Laiti, L., \& Chelazzi, L. (2003). Associative knowledge controls deployment of visual selective attention. Nature Neuroscience, 6, 182-189.

Morgan, J. L., \& Meyer, A. S. (2005). Processing of extrafoveal objects during multiple object naming. Journal of Experimental Psychology: Language, Memory, \& Cognition, 31, 428-442.

Morsella, E., \& Miozzo, M. (2002). Evidence for a cascade model of lexical access in speech production. Journal of Experimental Psychology: Learning, Memory, \& Cognition, 28, 555-563.

NAVARrete, E., \& Costa, A. (2005). Phonological activation of ignored pictures: Further evidence for a cascade model of lexical access. Journal of Memory \& Language, 53, 359-377.

Snodgrass, J. G., \& VAnderwart, M. (1980). A standardized set of 260 pictures: Norms for name agreement, image agreement, familiarity, and visual complexity. Journal of Experimental Psychology: Human Learning \& Memory, 6, 174-215.

Soto, D., Heinke, D., Humphreys, G. W., \& Blanco, M. J. (2005). Early, involuntary top-down guidance of attention from working memory. Journal of Experimental Psychology: Human Perception \& Performance, 31, 248-261.

ZeLINSKY, G. J., \& MURPHY, G. L. (2000). Synchronizing visual and 
language processing: An effect of object name length on eye movements. Psychological Science, 11, 125-131.

\section{NOTE}

1. The reaction time analysis for the first block revealed a main effect of target presence, with longer reaction times on target-absent than on target-present trials [952 vs. $801 \mathrm{msec} ; F_{1}(1,13)=40.70, \eta_{\mathrm{p}}^{2}=$ $.76 ; F_{2}(1,26)=62.94, \eta_{\mathrm{p}}^{2}=.71$, both $p$ s $\left.<.001\right]$ and a main effect of competitor presence, with longer reaction times in the presence than in the absence of a related competitor [896 vs. $857 \mathrm{msec} ; F_{1}(1,13)=$ $\left.13.77, p<.01, \eta_{\mathrm{p}}^{2}=.51 ; F_{2}(1,26)=11.88, \eta_{\mathrm{p}}^{2}=.31, p<.01\right]$. The eyemovement analyses did not yield any significant differences between the conditions.

\begin{tabular}{|c|c|c|c|}
\hline \multicolumn{4}{|c|}{$\begin{array}{l}\text { APPENDIX } \\
\text { Materials }\end{array}$} \\
\hline \multicolumn{2}{|c|}{$\begin{array}{c}\text { Table A1 } \\
\text { Homophone Set }\end{array}$} & \multicolumn{2}{|c|}{$\begin{array}{c}\text { Table A2 } \\
\text { Semantic Set }\end{array}$} \\
\hline Target & Related Competitor & Target & Related Competitor \\
\hline bat (animal) & bat (baseball bat) & arrow & bullet \\
\hline bow (arrow) & bow (ribbon) & bird & feather \\
\hline boy & buoy & cigarette & ashtray \\
\hline chest (trunk) & chest (body part) & comb & brush \\
\hline flower & flour & crown & sceptre \\
\hline glasses (spectacles) & glasses (wine glasses) & hammer & drill \\
\hline horn (antler) & horn (hooter) & hand & foot \\
\hline mouse (rodent) & mouse (computer mouse) & lock & key \\
\hline nail (finger nail) & nail (tool) & nose & eye \\
\hline nut (peanut) & nut (tool) & organ & church \\
\hline pipe (drainage pipe) & pipe (smoking) & plane & propeller \\
\hline spade (tool) & spade (card) & racket & shuttle \\
\hline table (furniture) & table (chart) & saddle & horse \\
\hline tank (fish tank) & tank (military) & shirt & trousers \\
\hline \multicolumn{2}{|c|}{$\begin{array}{l}\text { Fillers: anchor, ant, button, candle, chair, clock, face, } \\
\text { fence, fish, grapes, guitar, hair, hinge, horseshoe, } \\
\text { igloo, king, leaf, mitten, mushroom, necklace, plug, } \\
\text { purse, ruler, scissors, ship, snake, thermometer, tree. }\end{array}$} & \multicolumn{2}{|c|}{$\begin{array}{l}\text { Fillers: banana, bell, belt, bone, broom, butterfly, card, } \\
\text { cloud, duck, envelope, flag, football, hanger, hat, lad- } \\
\text { der, lollypop, pear, plaster, rabbit, saw, snowman, } \\
\text { swan, tie, toaster, torch, weight, whistle, wheel. }\end{array}$} \\
\hline
\end{tabular}

(Manuscript received January 25, 2006;

revision accepted for publication August 22, 2006.) 